\title{
Analysis on Language Development Stages of Infants
}

\author{
Wenling Jia \\ Gaoerzhuang School \\ Yigou Town, Tangyin County, Anyang City, China
}

\begin{abstract}
Children need a long time to adapt to the process of growing from newborns to independent individuals and from natural persons to social persons. The healthy growth of children depends on innate factors and acquired factors. Educators should have systematic and deep understanding for the occurrence and development of words, so as to carry out language education on children with purpose, and then help the healthy development of language competence of each child. Let children gain more happiness deep in heart and experience the charm of language. It is the first step to lay solid foundation for their life in the future.
\end{abstract}

\section{Keywords-Infants' language development; language education}

\section{INTRODUCTION}

In the 1950s, with the occurrence of psychological linguistics, people began to research the production and development of infants' language from the perspective of language acquisition. Language plays an important part in infants' cognition and social development.

F.de Saussure thinks langue and parole should be distinguished, namely distinguish social language from individual language. Parole means actual listening (comprehension process), speaking and writing (expression process). Langue can embody the function as communication tool through parole activities and become "living language". Infants' verbal process covers the occurrence and development of speech perception, speech comprehension and speech expression ability. Speech perception is a language competence acquired by infants in early stage.

\section{Pre-LANGUAge Stage}

Generally speaking, the period from the birth of infants to the occurrence of the first word with real meaning is classified as pre-language stage. The duration is 0 to 12 months. During this period, infants' speech perceptual ability, speech capacity and comprehensive ability for language gradually develop. They babble, make nonverbal sound and use gesture to communicate. They are called pre-language phenomenon or pre-language behavior.

\section{A. Pre-language Development of Speech Perception}

During the past twenty years, a lot of researches on infants' speech perception have shown that infants have heard the vast majority of pronunciation differences in human language in the first few weeks after birth; they can distinguish the voice of people from other sounds in different categories within one week after birth; infants of three to four months old have categorical perception on consonant and distinguish voiceless consonant from voiced consonant; when infants are 10 to 12 months old, their ability to distinguish and differentiate voices has matured. They can distinguish factors in first language and know about the meaning. Zhou Jing (1994) thinks in Chinese system, infants' pre-language stage is the voice sensitive period in language acquisition. Centering on the most external form of language-voice, infants develop three abilities, including pre-language perception ability, pre-language development ability and pre-language communicative ability. He divides the speech perception ability in the pre-language stage into three levels: tonal discrimination level ( 0 to 4 months), tonal modification level (4 to 10 months) and meaning recognition level (10 to 8 months). According to the latest research achievements over the past 20 years, we think the pre-language development of infants' speech perception can be divided into the following five stages:

1) The middle and later periods of gestation (five to eight months): Fetuses have has primary auditory response and original auditory memory. They can roughly distinguish tone, noise and voice and show preference for the voice of first language. Some fetuses can distinguish and memorize voices.

2) Neonatal period (0 to one month): Infants can position sounds, distinguish delicate difference of sounds according to physical characteristics of sounds and show obvious preference for voice (especially the mother's voice). Research (Zhang Lixia, 2006) has found newborns of one or two days old have obvious "synchronous reaction" to people's speech.

3) Pronunciation game period (two to three or four months): Infants have begun to understand some contact information in speech events, play "pronunciation games" with adults by "mutual imitation", distinguish and imitate voice and voiceless consonant and voiced consonant and gain speech perception ability.

4) Voice correction period (five to eight or nine months): Infants can distinguish the rhythm of speech and features of intonation and begin to change and correct their phonetic system according to phonetic environment around them. Voices that do not exist in the first language are gradually lost in this period.

5) Babbling period (nine to twelve months): Infants can distinguish factors in the first language, turn voices into factors and understand the meanings of voices. They can frequently and systematically imitate and learn voices to make preparation for speaking. 


\section{B. Pre-language Development of Voice}

Infants' voice acquisition process means voices appear after the first cry and develop in order of single syllable, disyllable, multi-syllable and meaningful voice. The sequence of occurrence and development of voices are determined by physiological maturity of vocal organs. Because the physical development of infants' vocal organs has common rules, the initial development of infants' voice also has universal rules.

\section{Development of Pre-language Communication}

In the year before infants can use language to communicate, they can use some specific voices and postures to exchange information, which also has three basic characteristics of parole, namely purpose, convention and indication. After occurrence, parole still plays the role of language substitutes in specific occasions.

\section{OCCURRENCE OF PAROLE}

Infants begin to speak when they are 10 to 14 months old.

\section{A. The Occurrence of the First Batch of Words and Its Ecology Analysis}

Infants can say the first word with specific meaning during 9 to 16 months old. Ecological studies on these words find they are context-bound, namely they can express a certain thing in certain circumstance (occasion). The words don't have general meaning but original indication, corresponding symbolism and communication meaning, just like accompaniments of certain things in specific occasion.

However, further researches find some among the first batch of words said by infants have general meanings. This discovery shows big differences exist among infants in the occurrence of parole. It overthrows the conclusion that "the first batch of words doesn't have general meaning" and estimates the time when parole occurs in strict sense is 10 months after birth.

\section{B. Acquisition and Use of Words}

In the occurrence stage of parole, the acquisition and application of infants' words mainly embody in three aspects: (1) continue to grasp some words with strong restriction of occasion (Barrett, 1983, 1986); (2) words that have been mastered begin to get rid of occasion restriction and acquire primary general meaning; (3) begin to directly grasp some words of summary and referential function. Getting rid of the occasion restriction of words is important way for infants to truly grasp words and acquire concepts. The outward manifestation is that words only used for specific occasions and certain things are applied to different occasions related to this thing.

Barrett bases on the core factor theory (Nelson, 1983, 1985; Barrett, 1983, 1986) to further raise the prototype theory about internal mechanism for infants to acquire and apply words at this stage. It explains specific phenomena in word acquisition very well such as "extension shrink", "extension enlargement" and "matching error" and gets powerful support and demonstration through experimental study and actual observed results, so it is acceptable (Pang Lijuan, Li Hui, 1999).

\section{DEVElopMent OF PAROLE}

Infants of 10 to 15 months old can grasp one to three new words on average monthly. In this way, they can say a batch of words in 15 months old. Thereafter, they grasp new words faster obviously. Infants of 19 months old have been able to say about 50 words. The speed for infants to grasp new words further and suddenly becomes faster. They can grasp 25 new words on average monthly. This is the phenomenon of "word explosion" when infants are 19 to 21 months old. Within two months after this period, infants can say the first batch of twoword sentence of certain tone. They leave the period of one word sentence and enter the period of world union and grammar generation.

\section{A. Occurrence and Mechanism of Two-Word Sentence}

Compared with one word sentence, two-word sentence can express the meaning more clearly and has the main basic parts of sentences. But it is still brief, intermittent and imperfect. It is more like the language used by people to send telegram, which is called telegram sentence; some use common words as the subject term and a word to indicate things, actions or attributive characters, which is called sentence with main words, such as "that book", "hey, balloon" and "more milk", etc. Correspondingly, there are also two generative rules of two-word sentence: one is mean axis open connection, namely use a common word as mean axis and connect a word related to things, actions and attributive characters before and after it to form sentence with main words; another is category corresponding connection, namely words from two categories (different kinds and properties) and with internal real meaning or specific relations combine to form telegram sentence.

\section{B. Grammar Acquisition}

A lot of researches have shown it is the critical period when infants are 20 to 30 months old to grasp grammar basically. After growing to 36 months old, infants basically grasp systematic grammar of the first language and become "speaker" with proficient expression ability. In the process that infants grasp grammar rules, excessive regularization or enlargement of rules generally exists, which is related to the absoluteness of infants' egocentric thinking (Pang Lijuan, Li Hui, 1999). People have proposed different hypothesis or theory to explain internal mechanism that infants acquire grammar, such as the transformational generative theory of Chomsky and analogous generative method of McWhinney.

\section{CONCLUSION}

Language is the product of socialization and has involved in social life of infants since they are born. Infants grow up in social environment. Proper language education will promote healthy development and growth of child. We should help children to better learn language by conforming to infants' physiological and psychological laws, absorb experience accumulated by human beings and explore the road to infants' 
language development to make contribution to healthy growth of our human beings.

\section{REFERENCES}

[1] Zhang Chungai, Wu Jiayi. Infant Scientific Feeding [M], Beijing: China Population Publishing House, 2001: 3-344

[2] Lin Chongde. Developmental Psychology [M], Beijing: People's Education Press, 2009: 152-160

[3] Ding Zuyin. Child Psychology [M], Beijing: People's Education Press, 1986:54-56

[4] Zhuang Wenzhong. Children's Language Teaching Method [M], Beijing: People's Education Press, 1987:26-145

[5] Yuan Xianzhen, Yan Ruying. Early Childhood Pedagogy [M], Beijing: People's Education Press, 1987:166-214. 